\title{
Multi-criteria decision-making methods in selecting seismic upgrading strategy of high-rise RC wall buildings
}

\author{
Mohammad Sadegh Es-haghi ${ }^{1}$, Mohammad Sadegh Barkhordari ${ }^{2}$, Zhenyu HUANG ${ }^{3}$, Jianqiao Ye ${ }^{4}$ \\ 1- Master of Science, Structural Engineering, School of civil engineering, Khajeh Nasir Toosi University \\ of Technology, Tehran, Iran ms es.haghi@yahoo.com \\ 2- Ph.D., Earthquake Engineering, Department of Civil and Environmental Engineering, Amirkabir \\ University of Technology, Tehran, Iran \\ 3- College of Civil and Transportation Engineering, Shenzhen University, Shenzhen 518060, China \\ 4- Department of Engineering, Lancaster University, Lancaster, LA1 4YR, UK
}

\begin{abstract}
Reinforced concrete (RC) structural walls are widely used in high-rise structures in earthquakeprone areas. Damaged by the earthquakes in the past decades, these buildings need retrofitting in order to increase the resilience of buildings with concrete shear walls. This study aimed to investigate the retrofitting of high-rise RC wall buildings using energy dissipation devices. To this end, a total of 4 buildings with 15, 20, 25, and 30 stories equipped with concrete shear walls as their lateral load-resisting system were retrofitted using passive seismic control systems. The buildings were subjected to the set of the far-field and near-field record presented in the Federal Emergency Management Agency (FEMA) P695, and an index was defined to relate the structural responses of the building, such as drift, acceleration, velocity, displacement, and base shear, to the earthquake records. The resulting index values were considered as the criterion, and the passive seismic control systems were ranked by the efficient multi-criterion decision-making (MCDM)
\end{abstract}


method. Based on the results from the MCDM and using the considered criteria, friction damper was ranked first among the avaiable energy dissipation devices for high-rise RC wall buildings.

Keywords: Reinforced concrete wall, High-rise buildings, MCDM method

\section{Introduction}

Large-magnitude earthquakes have caused severe damage to buildings and infrastructures over the past decades, imposing excessive costs both directly (such as building damage) and indirectly (such as the downtime) to societies. Buildings with concrete shear walls have been widely used in earthquake-prone areas to provide enhanced strength, stiffness, and ductility capacity against possible earthquakes. however they were severely damaged during previous earthquakes, compromising their performance [1-5]. In most cases, the damaged buildings were rebuilt due to the difficulties in repairing concrete shear walls and/or the fact that an required performance may not be ensured after repairing. Hence, concrete shear wall buildings, especially high-rise structures, are required to be appropreitely] retrofitted to minimize potential earthquake damage. The use of energy dissipation devices is one of the retrofitting methods, with passive seismic control systems as a subcategory of these devices attempting to absorb and dissipate earthquake energy through different techniques. However, a definite response is yet to be found to the question of which of the passive seismic control systems is the best option for retrofitting concrete shear wall buildings. The complexity of the problem arises from the fact that different parameters affect the structural responses, consequently changing the value of the criteria used in decision-making. For instance, 
each of the passive seismic control systems has its specific features and, therefore, leads to different results for the same building subject to the same earthquake.

On the other hand, structural responses are not identical since earthquake records have a random nature and their contents are different from one another. Moreover, as the building height increases, the effect of higher vibration modes on the structural response increases, changing the structural behavior and response under a given earthquake. The factors mentioned above add to the complexity of the problem and, since one or more responses of structure can be affected by each factor, different criteria, such as the acceleration and displacement of the stories as well as the base shear of the structure, should be taken into account. Hence, it can be stated that ranking and selecting the best option is not an easy task, and the multi-criterion decision-making (MCDM) method can be regarded as one of the approaches to tackle the problem. It should be noted that MCDM has been used in different fields of civil engineering [6-9]. Medineckiene et al. [10] presented a new MCDM-based method for sustainability assessment of buildings. They determined the weight of the criteria using the analytic hierarchic process (AHP) and developed a method to assess sustainability of buildings [10]. Similar studies have been conducted on applying MCDM theories in sustainable decision-makings in construction and building technology [11-13]. Formisano et al. [13] used three different MCDM methods, namely TOPSIS, ELECTRE, and VIKOR, to select the most optimal method for retrofitting RC buildings and for super-elevation of masonry buildings. All of their employed methods yielded similar results. Other researchers have also used the MCDM methods to determine the most suitable option for retrofitting buildings [14, 15]. These options have different features. 
The application of friction dampers, due to its characteristics, results in more reliable control over structural response under seismic excitement. For a nonlinear viscous damper, its damping ratio depends on the vibration frequency and maximum displacement of the two ends of the damper or modal displacement shape. Therefore, the preponderance of a friction damper over a nonlinear viscous damper is its independence of velocity and vibration frequency [48]. Although friction dampers make a structure stiffer, the stiffness is reduced due to damper slippage and when they are applied to resist small seismic and wind. Another issue is the effect of higher modes on the response of structures with concrete shear walls [49]. The secondary and even higher vibration modes of high-rise structures can boost the shear and flexural force demand. For instance, Yang et al. [50] showed structural responses rise with raising the earthquake magnitude due to higher modes engagement. As a result, the modal deformation and the associated internal forces are increased after plastic hinge formation at the wall base. A mass damper is designed based on the first mode frequency. Researches have confirmed that the TMD sensitivity to frequency change occurs in yield reduction. In a low-rise building, the use of base isolators can extend the period of the first mode, which in turn decreases the load exerted on the structure. However, the change in the first period is negligible in high-rise buildings, while the foremost cause for utilizing base isolators in high-rise buildings is to dissipate large portions of seismic energy. From the above discussions, it can be seen that choosing the most appropriate option for retrofitting a building is not a straightforward decision to be made.

There are a few studies that compared and ranked passive seismic control systems . In this regards, Caterino et al., [55] discussed how the MCDM framework might be applied to seismic retrofitting of sub-standard structures. They applied TOPSIS - MCDM method in under-designed short-rise buildings. In addition, Formisano et al [56] examined the seismic retrofitting of an existing
Commented [YJ2]: Excitations?

Commented [YJ3]: Less strong wind?

Commented [YJ4]: What do you mean? Stronger responses?

Commented [YJ5]: Always Full terms at first apperence

Commented [YJ6]: ??? confusing 
reinforced concrete school building using the TOPSIS-MCDM method, considering the economic, structural, and environmental aspects of the project. Recently, Barkhordari and Tehranizadeh [16] ranked passive seismic control systems by their effectiveness in reducing responses of concreteshear-wall buildings using the TOPSIS (technique for order preference by similarity to solution) method. However, there are some main disadvantages in the TOPSIS model, including correlations Commented [YJ9]: This should appear when you $1^{\text {st }}$ use TOPSIS. between criteria, uncertainty in obtaining the weights only by objective methods or subjective methods, and the possibility of alternatives close to an ideal point and nadir point concurrently [17]. The avaiable literature mostly assessed the effect of each of the passive seismic control systems separately on the response of concrete structures with concrete shear walls [18-23], while performance based multi-criteria decision-making methods in selecting seismic upgrading strategy of high-rise buildings are scarce.The study reported in this paper investigated the effect of some widely used passive seismic control systems on improving the performance of concrete shear walls and their prioritization. To this end, a total of five passive seismic control systems was considered, namely, tuned mass damper (TMD), viscoelastic damper, friction damper, viscous damper and the lead-core rubber bearing. Four high-rise buildings with 15, 20, 25, and 30 stories were designed and retrofitted using the passive seismic control systems. These five systems were, in fact, five options for retrofitting and improving the behavior of each of the buildings. These options were ranked for each building by defining a number of criteria based on the structural responses and using a well-organized MCDM method based on a multi-objective non-linear programming model. Thus, this paper presents an approach for ranking and selecting seismic upgrading strategy for high-rise RC wall buildings 


\section{Method}

In order to better investigate and assess the use of dampers and base isolators, four buildings of 15, 20, 25, and 30 stories were designed based on the ACI [24] and AISC [25] guidelines. RC shear walls were considered as the lateral force-resisting system for the buildings. The plan and cross-section of the buildings are shown in Fig. 1. As shown, the buildings consist of five 4-meter spans. The dead and live loads in the design were considered 5.5 and $2 \mathrm{kN} / \mathrm{m}^{2}$, respectively. The compressive strength of the concrete, the yield stress of the longitudinal and lateral rebars and the stirrups and the nominal yield strength of steel were, respectively, 40, 430, 470, and $350 \mathrm{MPa}$. The considered parameters for the building design are given in Table 1. The buildings were designed based on the modal response spectrum analysis using the first 15 modes [26]. The leaning columns are used to consider the gravity framing effects. The cross-sections of building members are presented in Table A.1 Appendix A. 


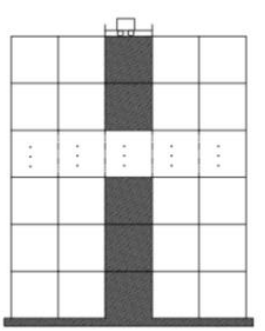

Tuned mass dampers

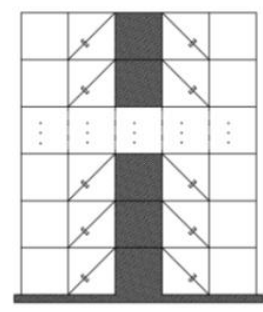

Viscous dampers
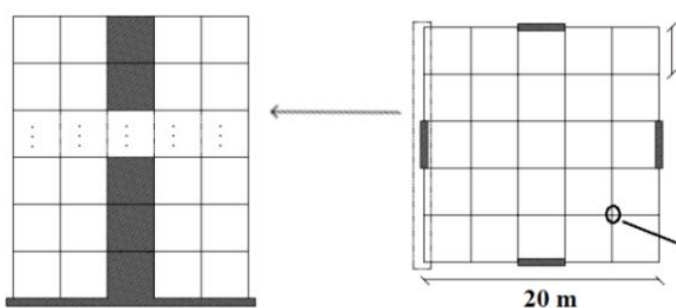

Typical plan and elevation of the base mode

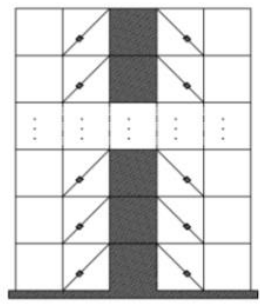

Friction dampers

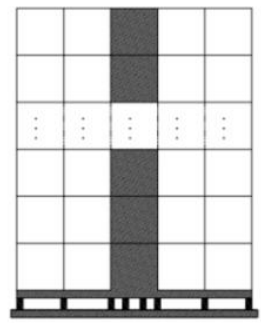

lead-rubber isolation bearing
$4 \mathrm{~m}$
물.

Figure 1. Typical plan and elevation of buildings

Table 1. The considered parameters for the building design

\begin{tabular}{|c|c|c|c|c|c|c|c|c|}
\hline \multicolumn{2}{|c|}{ Design Code } & \multirow{2}{*}{ Latitude } & \multirow{2}{*}{ Longitude } & \multirow{2}{*}{$\begin{array}{c}\text { Seismic design } \\
\text { category }\end{array}$} & \multirow{2}{*}{$\begin{array}{c}\text { Risk } \\
\text { category }\end{array}$} & \multirow{2}{*}{$\begin{array}{c}\text { Soil } \\
\text { classification }\end{array}$} & \multirow{2}{*}{$\begin{array}{c}\mathrm{S}_{\mathrm{s}} \\
(\mathrm{MCE})\end{array}$} & \multirow{2}{*}{$\begin{array}{c}\mathbf{S}_{1} \\
(\mathrm{MCE})\end{array}$} \\
\hline Steel & Concrete & & & & & & & \\
\hline $\begin{array}{c}\text { AISC } \\
360-10\end{array}$ & $\begin{array}{c}\text { ACI } \\
318-14\end{array}$ & 35.6535 & -120.4407 & $\mathrm{D}$ & I & D (stiff soil) & 1.5 & 0.6 \\
\hline
\end{tabular}

The buildings were modeled using the OpenSees software package [27, 28]. Given the symmetry

of the building, a 2D model consisting of a shear wall and its surrounding frame was used along with the leaning columns to model the building behavior. The leaning columns were linked to the main structure utilizing rigid truss elements to transfer the P-Delta effect [29].

To retrofit the structures, the five passive seismic control systems mentioned above were designed, respectively, based on [51], [52], [53], [54] and ASCE [26]. The dampers and base isolators were designed so as to provide damping ratio of $15 \%$. Table 2 shows the modal periods for each building
Commented [YJ10]: Only 4 types damper named in the

figure.
Commented [YJ11]: When you use symmetry in your model, the vibration modes you can simulate are symmetric modes, so some important models may go missing. 
[31]. The specifications of the designed passive seismic control systems are given in Tables 3 to

7. The elements and materials used for modeling the structural members and passive seismic control systems are also presented in Table 8.

The viscous damper is modeled with a Two Node Link Element. This element offers a viscous damper hysteretic response [32]. An equivalent uniaxial material composed of different materials and also a Two Node Link Element are used to model the friction damper [33]. The lead-rubber bearings are modeled with a ZeroLength Element and a uniaxial KikuchiAikenLRB material [34, 35], which generate non-linear hysteretic curves of the LRB isolators. To simulate the non-linear response of the RC walls, fiber-section model-based Timoshenko beam elements are utilized [36]. The tuned mass damper is modeled with a ZeroLength Element and Viscous and Elastic materials [37]. The Viscous and Elastic materials, as well as Two Node Link Element, are used to simulate the hysteretic response of the viscoelastic dampers. Beams and columns are modeled using DispBeamColumn elements, Steel02 and Concrete02 [27].

Table 2. Modal periods of the buildings

\begin{tabular}{ccccc}
\hline & \multicolumn{4}{c}{ Modal periods (sec) } \\
Fixed based & 15-story & 20-story & 25-story & 30-story \\
\cline { 2 - 5 } Friction & 2.66 & 3.17 & 3.8 & 4.3 \\
LRB & 1.59 & 1.86 & 2.08 & 2.63 \\
TMD & 2.98 & 3.39 & 3.89 & 4.38 \\
Viscous & 2.98 & 3.41 & 4.06 & 4.6 \\
\hline
\end{tabular}

Table 3. The non-linear viscous dampers

\begin{tabular}{|c|c|c|c|c|}
\hline & 15-story & 20-story & 25-story & 30-story \\
\hline$C \frac{K N \cdot \sec ^{0.5}}{m^{0.5}}$ & 597 & 611 & 810 & 922 \\
\hline
\end{tabular}

Table 4. Slip-load of friction dampers
Commented [YJ12]: Just an element?

Commented [YJ13]: Aa ZeroLength Element or ZeroLength Elements?

Commented [YJ14]: What is this? previously. 


\begin{tabular}{lllll}
\hline $\begin{array}{l}\text { Yield strength } \\
\text { (slip load) }\end{array}$ & 15-story & 20-story & 25-story & 30-story \\
\cline { 2 - 5 } & $170 K N$ & $130 K N$ & $141 K N$ & $150 K N$ \\
\hline
\end{tabular}

Table 5. The specifications of viscoelastic dampers

\begin{tabular}{|c|c|c|c|c|}
\hline & 15-story & 20-story & 25 -story & 30-story \\
\hline$C \frac{N \cdot \mathrm{sec}}{m}$ & $6.02 \times 10^{6}$ & $4.03 \times 10^{6}$ & $3.1 \times 10^{6}$ & $7.3 \times 10^{6}$ \\
\hline Damper stiffness & $6.48 \times 10^{6}$ & $5.24 \times 10^{6}$ & $4.46 \times 10^{6}$ & $13.3 \times 10^{6}$ \\
\hline Brace stiffness & $259.2 \times 10^{6}$ & $208 \times 10^{6}$ & $180 \times 10^{6}$ & $528 \times 10^{6}$ \\
\hline
\end{tabular}

Table 6. Tuned mass dampers

\begin{tabular}{lcccc}
\hline & 15-story & 20-story & 25-story & 30-story \\
\cline { 2 - 5 } Mass $($ ton $)$ & 45 & 60 & 75 & 90 \\
Stiffness $(K N / m)$ & 342.5 & 217.5 & 248.1 & 206 \\
$C_{d}=2 \xi m_{d} \omega_{d}\left(\frac{N . s e c}{m}\right), \xi=0.145$ & 26050 & 26784 & 28728 & 28512 \\
\hline
\end{tabular}

Table 7. Lead-rubber isolation bearing

\begin{tabular}{lcccc}
\hline & 15-story & 20-story & 25-story & 30-story \\
\cline { 2 - 5 } Area of rubber $\left(\mathrm{m}^{2}\right)$ & 0.442 & 0.57 & 0.7 & 1.227 \\
Thickness of rubber $(\mathrm{m})$ & 0.65 & 0.8 & 0.95 & 1.15 \\
Shear modulus of rubber $\left(N / \mathrm{m}^{2}\right)$ & $64.0 \times 10^{4}$ & $64.0 \times 10^{4}$ & $64.0 \times 10^{4}$ & $64.0 \times 10^{4}$ \\
Area of lead plug $\left(\mathrm{m}^{2}\right)$ & 0.0254 & 0.038 & 0.038 & 0.057 \\
Yield stress of lead plug $\left(N / \mathrm{m}^{2}\right)$ & $8.82 \times 10^{6}$ & $8.82 \times 10^{6}$ & $8.82 \times 10^{6}$ & $8.82 \times 10^{6}$ \\
\hline
\end{tabular}

Table 8. Details of employed elements and materials

\begin{tabular}{ccc} 
Table 8. Details of employed elements and materials & \\
\cline { 2 - 3 } Beam and Column & Element & Material \\
RC shear wall & DispBeamColumn & Steel02 \\
Friction damper & TimoshenkoBeamColumn & Steel02, MCFT ND Material \\
LRB isolator & TwoNodeLink & Steel02, Elastic, and Series \\
Tuned mass damper & ZeroLength & KikuchiAikenLRB, AxialSp and Elastic \\
Viscous damper & ZeroLength & Viscous and Elastic \\
Viscoelastic damper & TwoNodeLink & ViscousDamper \\
\hline
\end{tabular}


An essential issue in structural engineering is to assess the seismic performance of structures in the non-linear range against ground motion records [38]. Numerous approximate methods have been presented to estimate structural response within the range of non-linear behavior, one of the most accurate of which is the time-history analysis. On the other hand, since the difference in the pecifications of ground motion records leads to critical differences in the structural response, the set of 22 far-field and 28 near-field records presented in the Federal Emergency Management Agency (FEMA) P695 was utilized [39]. The characteristics of the selected ground motions can be found in FEMA P695 [39]. All the ground motion records were scaled for the maximum considered earthquake (MCE) hazard level [26]. In other words, the average value of the 5\% damped response spectra for the suit of motions (from $0.2 \mathrm{~T}$ to $1.5 \mathrm{~T}$, where $\mathrm{T}$ is the first mode of vibration) is not less than the ASCE design response spectrum [26].

All non-linear time-history analyses adopted the Newmark time integration method of constant acceleration. Damping of $2 \%$ based on the Rayleigh damping model was considered and applied to the building members. It is possible to achieve greater numerical stability by altering the solution algorithm. Therefore, the Newton-Raphson method was used as a default as it provides greater computational efficiency than the Modified Newton-Raphson method deos. If there are stability issues encountered with the Newton-Raphson method, the algorithm will be changed to the Modified Newton-Raphson. The convergence of the algorithm was based on the relative work increment. Responses of the buildings (15, 20, 25, and 30 stories) subjected to the ground motion (No. 1) recorded at the Brawley Airport station during the 1979 Imperial Valley earthquake are given here as an example (Figures 2 to 6). Figures 2-6 show the differences between the responses computed from the different methods.

Commented [YJ16]: What different methods? 
- Fixed base

- Friction Damper

- Tuned Mass Damper (TMD)

-.Viscous Damper

- Viscoelastic Damper

- Lead-Core Rubber Bearing (LRB)

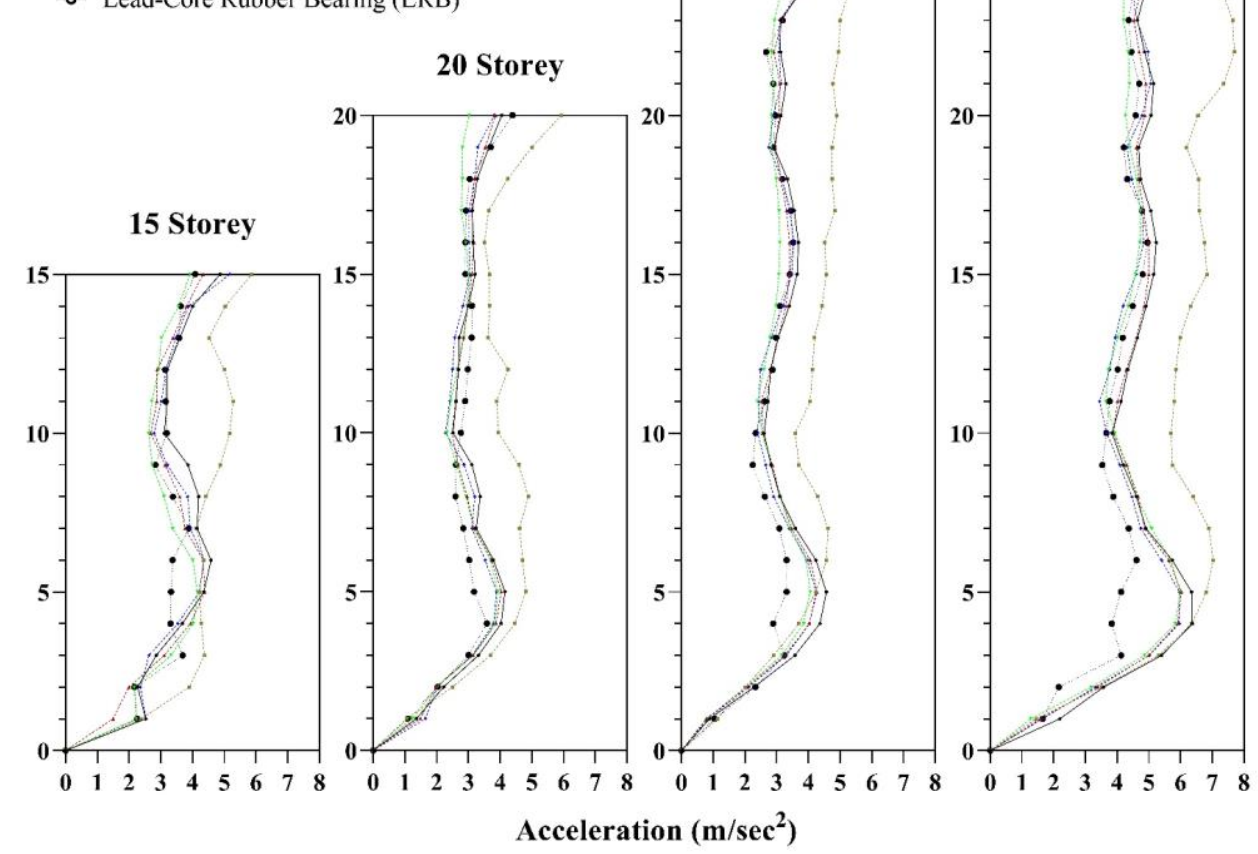

Figure 2. Responses (Acceleration) of the buildings subjected to the Imperial Valley earthquake 
- Fixed base

- Friction Damper

- Tuned Mass Damper (TMD)

* Viscous Damper

- Viscoelastic Damper

- Lead-Core Rubber Bearing (LRB)

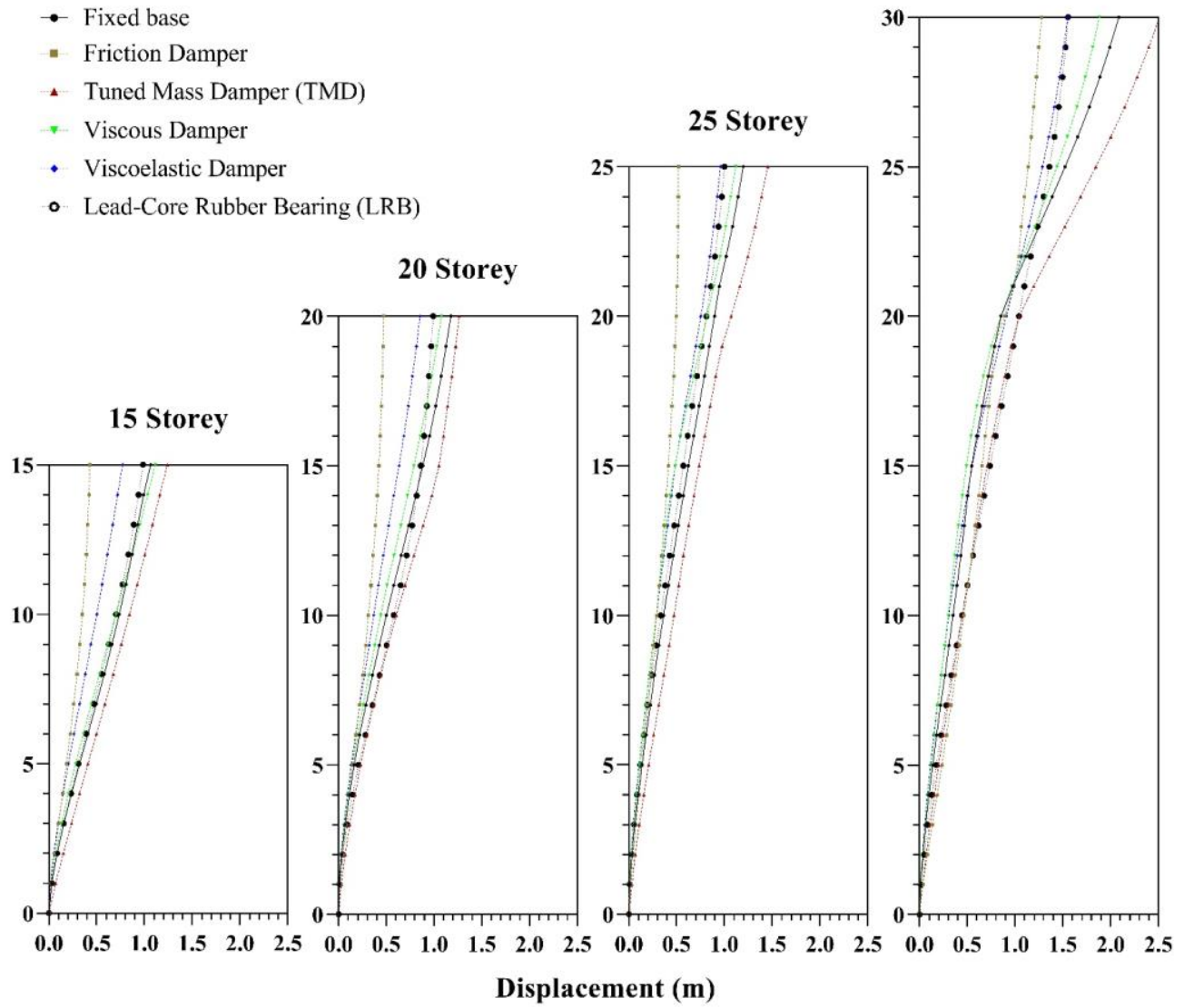

Figure 3. Responses (Displacement) of the buildings subjected to the Imperial Valley earthquake

30 Storey 


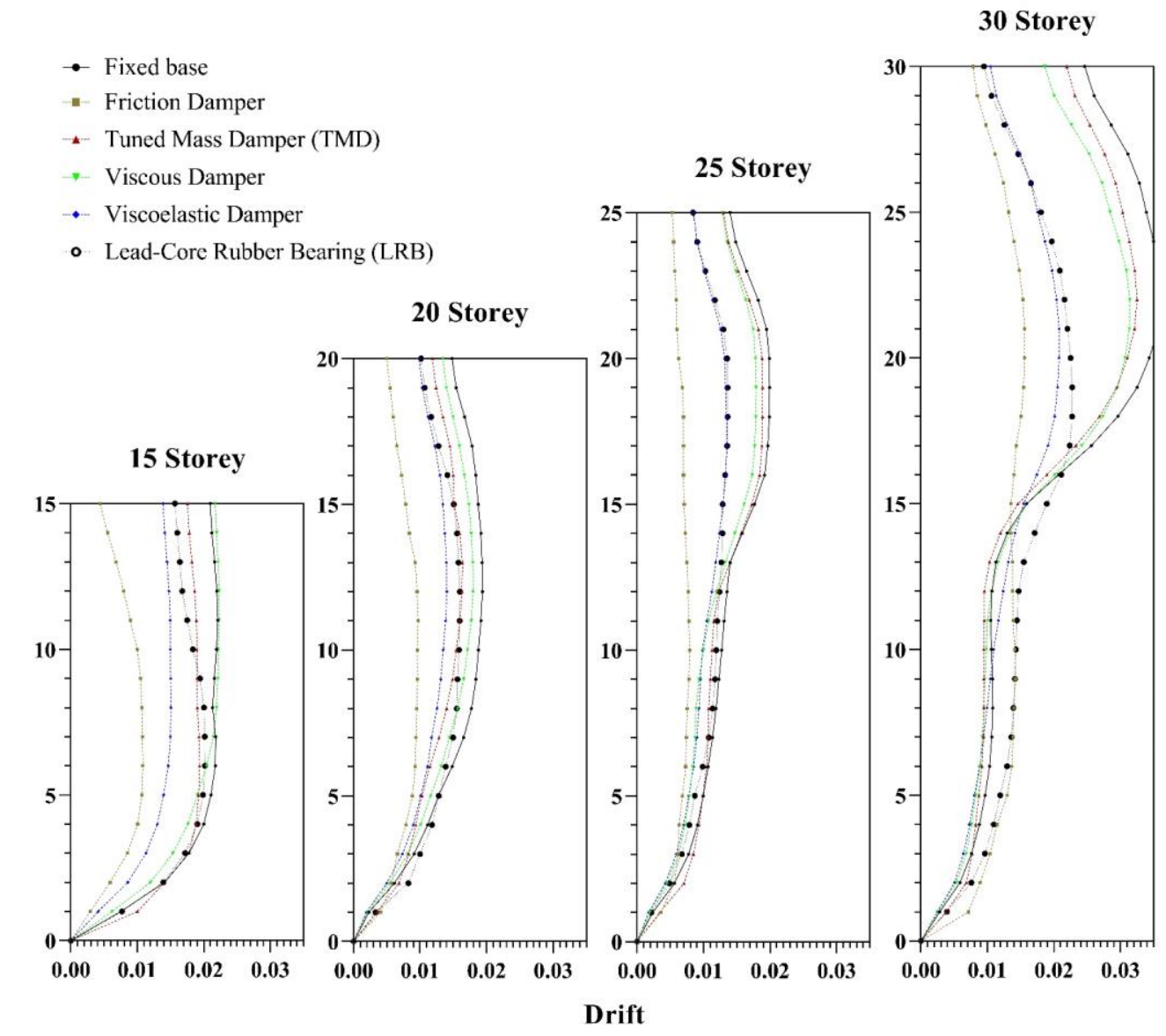

Figure 4. Responses (Drift) of the buildings subjected to the Imperial Valley earthquake 


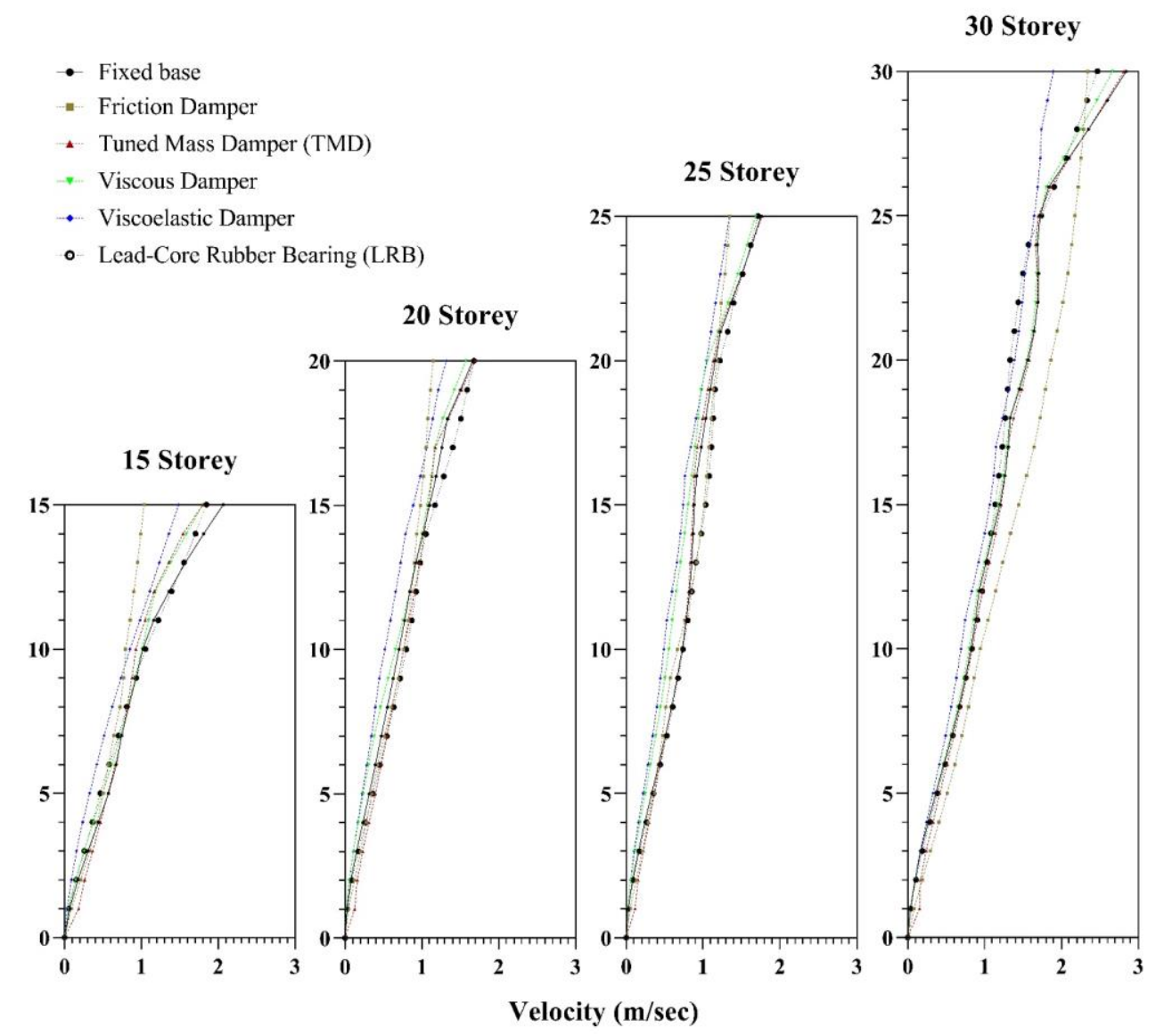

Figure 5. Responses (Velocity) of the buildings subjected to the Imperial Valley earthquake 
- Fixed base

- Friction Damper

-. Tuned Mass Damper (TMD)

- Viscous Damper

- Viscoelastic Damper

- Lead-Core Rubber Bearing (LRB)
30 Storey

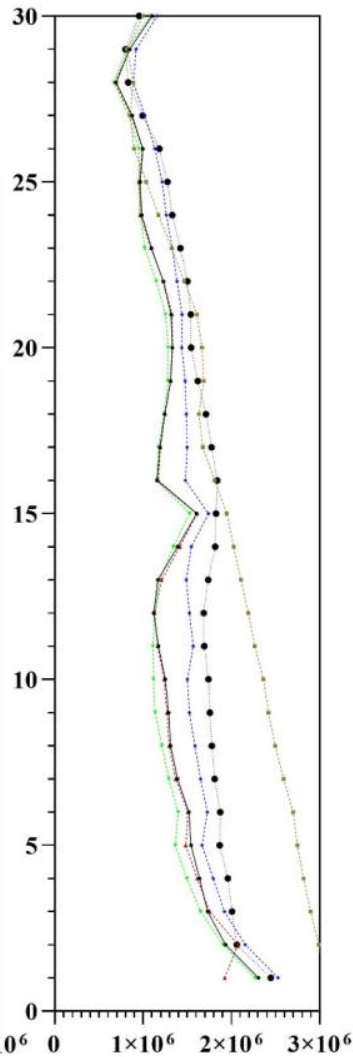

$1 \times 10^{6} \quad 2 \times 10^{6} \quad 3 \times 10^{6}$

\section{Shear Force (N)}

Figure 6. Responses (Shear Force) of the buildings subjected to the Imperial Valley earthquake

\section{Multi-criterion decision-making (MCDM)}

Multi-criterion decision-making is often used for specific problems with multiple qualitative and quantitative indices such as cost, level of importance and capacity. In such a ases, the objective is to consider all indices simultaneously and finding a solution in which the resultant of the desirability of all indices is maximized. In this study, the MCDM was used to prioritize the options 
(i.e., passive control systems) for retrofitting buildings with shear walls. Given that the frequency contents of the earthquakes are different and can affect the structural responses, the indicator expressed in Eq. 1 was defined to monitor the effect of inputs, i.e., the frequency content of the earthquake record, on the responses:

$$
\left\{\begin{array}{l}
\text { IndicatorValue }(I V)=\Delta E D P-\Delta S a \\
\Delta E D P=\left(\frac{E D P_{n}-E D P_{\min }}{E D P_{\max }-E D P_{\min }}\right)-\left(\frac{E D P_{n-1}-E D P_{\min }}{E D P_{\max }-E D P_{\min }}\right) \\
\Delta S a=\left(\frac{S a_{n}-S a_{\min }}{S a_{\max }-S a_{\min }}\right)-\left(\frac{S a_{n-1}-S a_{\min }}{S a_{\max }-S a_{\min }}\right)
\end{array}\right.
$$

In Equation 1, the engineering demand parameter (EDP) is a structural response (e.g., drift), and $S a$ represents the seismic scale factor. An indicator value is obtained by using Eq. 1 for each of the structural responses (acceleration, drift, velocity, displacement, and base shear). A higher indicator value indicates that the adopted system has a less satisfactory performance in controlling the respective structural response (non-beneficial criteria). The decision matrix is then formed after calculating the indicator values for all structural responses and buildings. The decision matrix for each building is given in Table 9, where the columns are the indicator values corresponding to each criterion for each of the buildings with passive control systems. The simultaneous evaluation

\begin{tabular}{|c|c|c|c|c|c|c|c|c|c|c|c|c|c|c|c|c|c|c|c|c|c|}
\hline \multirow{3}{*}{$\equiv \frac{n}{\frac{n}{\sigma}}$} & \multirow[b]{3}{*}{ Story } & \multicolumn{20}{|c|}{ Index } \\
\hline & & \multicolumn{4}{|c|}{ Acc. } & \multicolumn{4}{|c|}{ Disp. } & \multicolumn{4}{|c|}{ Drift } & \multicolumn{4}{|c|}{ Base Sh. } & \multicolumn{4}{|c|}{ Vel. } \\
\hline & & 15 & 20 & 25 & 30 & 15 & 20 & 25 & 30 & 15 & 20 & 25 & 30 & 15 & 20 & 25 & 30 & 15 & 20 & 25 & 30 \\
\hline \multicolumn{2}{|c|}{ Friction } & $\stackrel{\bullet}{\triangleleft}$ & $\stackrel{\sim}{\infty}$ & & $\stackrel{\vec{\sim}}{\underline{\Delta}}$ & $\begin{array}{l}\infty \\
u_{u}^{\prime}\end{array}$ & $\begin{array}{l}\text { un } \\
\text { a }\end{array}$ & $\stackrel{\vec{\omega}}{\dot{\omega}}$ & 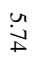 & $\dot{\vec{N}}$ & $\underset{\infty}{\phi}$ & $\stackrel{\vec{\omega}}{ \pm}$ & $\ddot{=}$ & $\ddot{8}$ & $\overrightarrow{\text { ï }}$ & $\stackrel{+}{\stackrel{\omega}{\omega}}$ & ù & $\dot{\vec{N}}$ & $\ddot{a}$ & $\begin{array}{l}u_{1} \\
\ddot{\text { ln }}\end{array}$ & $\ddot{0}$ \\
\hline \multicolumn{2}{|c|}{ LRB } & $\begin{array}{l}\bullet \\
\dot{\omega}\end{array}$ & $\stackrel{\sim}{\sim}$ & 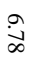 & రి & $\bar{N}$ & 。 & ن & $\overline{i r}$ & $\dot{w}_{0}^{\infty}$ & $\stackrel{\sim}{\sim}$ & $\dot{a}$ & $\stackrel{\infty}{\dot{N}}$ & $\dot{a}$ & $\begin{array}{l}u \\
\infty \\
\infty\end{array}$ & un & $\stackrel{\oplus}{\underset{\infty}{*}}$ & $\begin{array}{l}0 \\
\dot{b}\end{array}$ & $\underset{\infty}{\infty}$ & $\frac{a}{6}$ & $\overrightarrow{\ddot{y}}$ \\
\hline \multicolumn{2}{|c|}{ TMD } & $\begin{array}{l}0 \\
\text { i } \\
\text { N }\end{array}$ & $\stackrel{ }{y}$ & 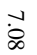 & i & 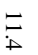 & $\begin{array}{l}\infty \\
\dot{\sigma}\end{array}$ & $\underset{\text { in }}{0}$ & $\vec{\omega}$ & $\stackrel{\infty}{\infty}$ & $\underset{\omega}{\infty}$ & $\underset{N}{i}$ & $\stackrel{0}{0}$ & $\stackrel{\partial}{0}$ & 古 & $\ddot{n}$ & $\dot{u}_{n}$ & $\stackrel{\sim}{\sim}$ & $\vec{i}$ & un & $\begin{array}{l}u \\
\dot{t}\end{array}$ \\
\hline
\end{tabular}
of criteria and alternatives (SECA) [40] was used to rank the passive control systems.
Commented [YJ18]: Give numbers to all equations, including this one.

Commented [YJ19]: Which one is eq(1)? 


\begin{tabular}{|c|c|c|c|c|c|c|c|c|c|c|c|c|c|c|c|c|c|c|c|c|}
\hline Viscous & $\begin{array}{l}0 \\
i \\
\infty\end{array}$ & $\underset{\omega}{\infty}$ & $\stackrel{v}{\sigma}$ & $\underset{\tilde{U}}{\overrightarrow{0}}$ & $\begin{array}{l}\infty \\
\dot{\sigma}\end{array}$ & $\underset{\infty}{0}$ & 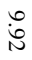 & 兽 & $\underset{\infty}{\stackrel{\infty}{0}}$ & $\begin{array}{l}0 \\
\stackrel{N}{N}\end{array}$ & $\stackrel{0}{\square}$ & $\stackrel{0}{0}$ & $\stackrel{\vec{\omega}}{\vec{\omega}}$ & $\dot{\omega}_{\infty}$ & $u_{\omega}^{u}$ & $\dot{a}$ & ㅊํㅇ & iv & $\dot{\hat{\phi}}$ & $u_{u}^{u}$ \\
\hline Vis. Ela. & $\underset{i}{0}$ & $\overrightarrow{i n}$ & $\dot{\vec{u}}$ & $\dot{w}_{\infty}$ & $\varpi_{\infty}$ & $\stackrel{\circ}{+}$ & iु & iे & 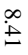 & $\stackrel{\vartheta}{y}$ & 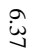 & 员 & $\dot{a}$ & $\stackrel{u}{\ddot{\nu}}$ & $\overrightarrow{i n}$ & $\infty$ & $\stackrel{\infty}{i}$ & $\dot{\infty}_{\infty}^{\infty}$ & $\underset{\infty}{\stackrel{\infty}{\infty}}$ & $\begin{array}{l}u \\
\text { N }\end{array}$ \\
\hline
\end{tabular}

\subsection{Simultaneous Evaluation of Criteria and Alternatives}

The simultaneous evaluation of criteria and alternatives (SECA) [40], which is based on a multiobjective non-linear mathematical model, was used to handle the MCDM problem in this study. Two types of reference points are considered for the criteria in this method. The first type is the standard deviation obtained for a given criterion, and the second type is the correlation between the values of different criteria. In SECA, the multi-objective model tries to minimize the deviation of criteria weights from the reference points and maximize the overall performance of each alternative. The steps involved in the SECA method are briefly explained below. Assuming $\mathrm{n}$ options and $\mathrm{m}$ criteria for a problem and that the weights of the criteria $\left(w_{j}, j=1, \ldots, m\right)$ are unknown, the decision matrix is as follows:

$$
X=\left[\begin{array}{cccc}
x_{11} & x_{12} & \ldots & x_{1 m} \\
x_{21} & x_{22} & \ldots & x_{2 m} \\
\vdots & \vdots & \vdots & \vdots \\
x_{n 1} & x_{n 2} & \ldots & x_{n m}
\end{array}\right]
$$

where $x_{i j}$ indicates the index value of the $i^{\text {th }}$ option corresponding to $j^{\text {th }}$ criterion. The matrix in Eq. 1 can then be normalized by using Eq. 2: 


$$
x^{N}{ }_{i j}= \begin{cases}\frac{x_{i j}}{\operatorname{Max}\left(x_{k j}\right)} & \text { if } j \in B C \\ \frac{\operatorname{Min}\left(x_{k j}\right)}{x_{i j}} & \text { if } j \in N C\end{cases}
$$

where $\mathrm{NC}$ and $\mathrm{BC}$ are the sets of non-beneficial and beneficial criteria, respectively.

The standard deviation of each criterion is a measure of its variations and can be obtained by grouping the normalized values of each criterion in a vector, denoted by $V_{j}\left(V_{j}=\left[x^{N}{ }_{i j}\right]_{n \times 1}\right)$, and calculating the standard deviation. In order to calculate the variations between the criteria, the correlation between each pair of vectors of criteria is calculated. The standard deviations obtained for the data of different buildings are given in Table 10. The correlation between each pair of vectors of criteria for different buildings is shown in Table 11.

\begin{tabular}{lccccc}
\hline \multicolumn{6}{l}{ Table 10. $\sigma_{j}$ values calculated for different structures } \\
\hline & Acc. & Disp. & Drift & Base Sh. & Vel. \\
\cline { 2 - 6 } 15-story & 0.0406 & 0.141 & 0.076 & 0.033 & 0.0776 \\
20-story & 0.0151 & 0.2064 & 0.179 & 0.1168 & 0.122 \\
25-story & 0.0698 & 0.215 & 0.177 & 0.0714 & 0.0589 \\
30-story & 0.179 & 0.227 & 0.178 & 0.104 & 0.0676 \\
\hline
\end{tabular}




\begin{tabular}{|c|c|c|c|c|c|c|c|c|c|c|c|c|c|c|c|c|c|c|c|c|}
\hline \multirow{3}{*}{ 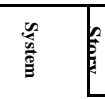 } & \multicolumn{20}{|c|}{ Index } \\
\hline & \multicolumn{4}{|c|}{ Acc. } & \multicolumn{4}{|c|}{ Disp. } & \multicolumn{4}{|c|}{ Drift } & \multicolumn{4}{|c|}{ Base Sh. } & \multicolumn{4}{|c|}{ Vel. } \\
\hline & 15 & 20 & 25 & 30 & 15 & 20 & 25 & 30 & 15 & 20 & 25 & 30 & 15 & 20 & 25 & 30 & 15 & 20 & 25 & 30 \\
\hline Friction & - & & - & - & 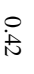 & $\begin{array}{l}\dot{\tilde{o}} \\
\dot{0}\end{array}$ & $\begin{array}{l}8 \\
\text { ¿ } \\
\text { t }\end{array}$ & $\begin{array}{l}\stackrel{\infty}{\infty} \\
\stackrel{\infty}{=}\end{array}$ & i & 这 & $\begin{array}{l}\stackrel{\circ}{\infty} \\
\dot{o} \\
\stackrel{\alpha}{\alpha}\end{array}$ & $\stackrel{\circ}{\stackrel{u}{u}}$ & $\dot{b}_{\vec{t}}$ & $\grave{0}$ & 总 & $\underset{\infty}{\dot{b}}$ & $\dot{\dot{\omega}}$ & $\begin{array}{l}\dot{b} \\
\dot{\infty}\end{array}$ & $\begin{array}{l}\text { in } \\
\text { 崩 }\end{array}$ & 兑 \\
\hline LRB & 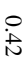 & $\begin{array}{l}\dot{\theta} \\
\dot{\tilde{O}}\end{array}$ & $\begin{array}{l}\stackrel{0}{0} \\
\text { fै }\end{array}$ & $\begin{array}{l}\stackrel{\infty}{\infty} \\
\stackrel{\infty}{=}\end{array}$ & - & - & - & - & $\dot{\theta}$ & $\dot{8}$ & $\begin{array}{l}\stackrel{8}{0} \\
\text { Wू }\end{array}$ & $\begin{array}{l}\text { O } \\
\text { 汖 }\end{array}$ & $\dot{8}$ & $\stackrel{\circ}{\infty}$ & 总 & 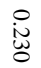 & ல̀ & ஜ & 怘 & 它 \\
\hline TMD & $\underset{\text { i }}{\text { U }}$ & ஜ் & 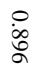 & 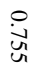 & : & $\dot{8}$ & $\begin{array}{l}\text { : } \\
\text { on }\end{array}$ & $\begin{array}{l}\text { : } \\
\text { 䜤 }\end{array}$ & - & - & - & - & 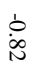 & $\stackrel{8}{\dot{\theta}}$ & 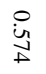 & 芯 & in & :्ञ & $\underset{\sim}{\stackrel{i}{\sim}}$ & d. \\
\hline Viscous & $\dot{i}_{i}$ & $\dot{0}$ & $\underset{\text { i্ }}{\stackrel{\text { }}{\alpha}}$ & $\underset{\infty}{\dot{\infty}}$ & $\begin{array}{l}\dot{0} \\
\dot{\infty}\end{array}$ & $\stackrel{\circ}{\infty}$ & 离 & $\begin{array}{l}\text { 总 } \\
\text { O }\end{array}$ & $\begin{array}{l}\dot{b} \\
\text { io } \\
\text { N }\end{array}$ & $\stackrel{\circ}{\circ}$ & ن & 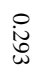 & - & - & - & - & 宓 & 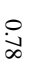 & 見 & $\begin{array}{l}\text { bे } \\
\text { 岕 }\end{array}$ \\
\hline Vis. Ela. & 完 & $\begin{array}{l}\dot{1} \\
\dot{\infty}\end{array}$ & $\begin{array}{l}\text { in } \\
\text { 崩 }\end{array}$ & $\begin{array}{l}\dot{b} \\
\dot{d} \\
\dot{d}\end{array}$ & ì & $\stackrel{\circ}{\dot{0}}$ & 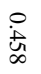 & $\stackrel{\dot{\sim}}{\stackrel{\sim}{\sim}}$ & in & ì & 岕 & $\stackrel{\dot{d}}{\stackrel{0}{*}}$ & 它 & $\stackrel{\circ}{\infty}$ & $\begin{array}{l}\dot{d} \\
\dot{d} \\
\text { dus }\end{array}$ & $\begin{array}{l}\dot{0} \\
\text { 怘 } \\
\text { S }\end{array}$ & - & - & - & - \\
\hline
\end{tabular}

Denoting the correlation between the $j^{\text {th }}$ and the $i^{\text {th }}$ vectors by $r_{i j}$, the conflict value between the $j^{\text {th }}$ criterion and the other criteria are calculated as follows:

$$
\pi_{j}=\sum_{l=1}^{m}\left(1-r_{i j}\right)
$$

After calculation, $\sigma_{j}$ and $\pi_{j}$ can be normalized, as shown in Eq. 4:

$$
\sigma_{j}^{N}=\frac{\sigma_{j}}{\sum_{l=1}^{m} \sigma_{l}}, \pi_{j}^{N}=\frac{\pi_{j}}{\sum_{l=1}^{m} \pi_{l}}
$$

In this method, the significance of a criterion is increased as its standard deviation, as well as the conflict between the data of a criterion and other criteria, are increased. Ultimately, using a multiobjective non-linear programming model (Eqs. 5 to 7) and the techniques of multi-objective optimization (Eq. 8), the weight of the criteria and the ranking of the options are simultaneously obtained as follows: 


$$
\begin{aligned}
& \max S_{i}=\sum_{j=1}^{m} w_{j} x_{i j}^{N} \quad \forall i \in\{1,2, \ldots, n\} \\
& \min \lambda_{b}=\sum_{j=1}^{m}\left(w_{j}-\sigma_{j}^{N}\right)^{2} \\
& \min \lambda_{c}=\sum_{j=1}^{m}\left(w_{j}-\pi_{j}^{N}\right)^{2} \\
& \max Z=\lambda_{a}-\beta\left(\lambda_{b}+\lambda_{c}\right), \text { s.t } \lambda_{a} \leq S_{i}, \quad \beta=3.0
\end{aligned}
$$

Where $w_{j}$ is the weight of the criteria, $\lambda_{a}$ is the coefficient of the overall performance score of alternatives, and $S_{i}$ is the overall performance score of each alternative.

It should be noted that the MCDM problem was solved using the LINGO 17 software and SECA

\begin{tabular}{|c|c|c|c|c|c|c|c|c|}
\hline \multirow{2}{*}{ System } & \multicolumn{4}{|c|}{ Rank } & \multicolumn{4}{|c|}{ Score } \\
\hline & 15 & 20 & 25 & 30 & 15 & 20 & 25 & 30 \\
\hline Friction & 1 & 1 & 1 & 1 & 0.215 & 0.245 & 0.244 & 0.240 \\
\hline LRB & 5 & 2 & 4 & 4 & 0.187 & 0.193 & 0.188 & 0.184 \\
\hline TMD & 3 & 3 & 3 & 5 & 0.195 & 0.190 & 0.191 & 0.163 \\
\hline Viscous & 2 & 5 & 5 & 3 & 0.208 & 0.180 & 0.176 & 0.194 \\
\hline Vis. Elastic & 4 & 4 & 2 & 2 & 0.192 & 0.190 & 0.199 & 0.216 \\
\hline
\end{tabular}
method [41]. Tables 12 and 13 present the calculated weights for the criteria and the ranking of the options obtained using the SECA method, respectively.

\begin{tabular}{c|cccc|cccc}
\hline \multicolumn{7}{c}{ Table 12. Calculated weight using the SECA method for the criteria } \\
\multicolumn{1}{c}{ Story } & 15 & 20 & 25 & 30 & 15 & 20 & 25 & 30 \\
\hline W(1) & 0.166 & 0.293 & 0.145 & 0.202 & Acc. & Acc. & Acc. & Acc. \\
W(2) & 0.250 & 0.182 & 0.222 & 0.203 & Disp. & Disp. & Disp. & Disp. \\
W(3) & 0.174 & 0.155 & 0.201 & 0.183 & Drift & Drift & Drift & Drift \\
W(4) & 0.221 & 0.159 & 0.216 & 0.203 & $\begin{array}{c}\text { Base } \\
\text { Sh. }\end{array}$ & $\begin{array}{c}\text { Base } \\
\text { Sh. }\end{array}$ & $\begin{array}{c}\text { Base } \\
\text { Sh. }\end{array}$ & $\begin{array}{c}\text { Base } \\
\text { Sh. }\end{array}$ \\
W(5) & 0.187 & 0.208 & 0.214 & 0.207 & Vel. & Vel. & Vel. & Vel. \\
\hline
\end{tabular}


Considering Figs. 2-6 and Table 13, the friction damper ranks first among the available options for all buildings, which can be attributed to the characteristics offered by the friction damper compared to the other dampers and LRB. Unlike the viscoelastic and viscous dampers, the performance of the friction dampers is not dependent on the loading frequency and velocity. In addition to exhibiting a stable and reliable behavior, the friction dampers are generally inexpensive. These dampers offer large rectangular hysteresis loops [42]. In addition to their considerable energy dissipation capacity, they increase the structural stiffness, which is lost after the sliding of the dampers. Once activated under earthquakes, these dampers generate a constant force at all earthquake levels, thus making the design of the connections and elements of the system more economical. To compare the friction and viscous dampers, it should be noted that the external force generated by the viscous dampers is dependent on velocity [43]. Since velocity and displacement have a phase difference, the damper force and the force generated in the structure may not coincide due to maximum displacement, even when part of the structure enters a nonlinear mode. This, in turn, decreases the maximum base shear of the structure with viscous dampers.

TMD is generally designed for a particular mode (e.g., the first mode), thus offering a poorer performance in high-rise buildings, as reported in the literature [44]. Base isolators are also generally more effective in low-rise buildings as they add a rigid mode shape to the modes and increase the structural period, thus dissipating the structural energy and reducing the acceleration exerted on the structure. Although note that base isolators are also used for high-rise buildings to reduce the energy entering the structure by the earthquake [45, 46]. As a suggestion, instead of at a single location, the TMD and LRB can be used at multiple locations along with the building height, for example, at different stories at one-third and two-thirds of the structure height. 
However, this is a mere example, and the performance should be scientifically investigated. In

most cases, only a single TMD is installed at building ceiling, which requires taking into account a large concentrated mass as the overhead at some points in the respective story, as well as considering a large space to install this mass. More importantly, sunch a concentrated mass should be considered in the design.

To further investigate and evaluate the SECA ranking, a different and indepedent ranking method is used in the next section .

\subsection{VIKOR method}

The VIKOR method [47], a Serbian acronym for VlseKriterijumska Optimizacija I Kompromisno Resenje, means multi-criteria optimization and compromise solution. This method is a multicriteria decision-making approach for solving decision-making problems with inappropriate criteria and different conflicting measurement units. The method is designed for and focused on ranking and selecting a solution from among a set of solutions in problems with conflicting criteria. The steps involved in the VIKOR method are briefly explained in this section first. The results are then compared to those obtained from the SECA method. The weights of the criteria for using VIKOR method were determined using the Shannon entropy concept and shown in Table 14.

Commented [YJ22]: Rererence is required.

\begin{tabular}{c|cccc}
\hline Table 14. Weights obtained using the entropy method \\
\hline & \multicolumn{4}{|c}{ Weight } \\
\cline { 2 - 5 } Acceleration & 0.045 & 0.003 & 0.04 & 0.194 \\
Displacement & 0.591 & 0.412 & 0.494 & 0.47 \\
Drift & 0.15 & 0.335 & 0.391 & 0.252
\end{tabular}




\begin{tabular}{c|cccc} 
Base Shear & 0.03 & 0.114 & 0.044 & 0.059 \\
Velocity & 0.181 & 0.134 & 0.029 & 0.024 \\
\hline
\end{tabular}

The steps of the VIKOR algorithm are as follows:

- First step: Determine the best and worst values from among the values obtained for the criteria

$$
\begin{aligned}
& \text { benefit-criteria }: f_{j}^{*}=\max _{i} x_{i j}, f_{j}^{-}=\min _{i} x_{i j}, \quad i=1, \ldots, m, j=1, \ldots, n \\
& \text { non-benefit-criteria }: f_{j}^{*}=\min x_{i j}, f_{j}^{-}=\max x_{i j}, i=1, \ldots, m, j=1, \ldots, n
\end{aligned}
$$

Where $\mathrm{m}$ is the number of feasible alternatives, and $\mathrm{n}$ is the number of criteria.

- Second step: Compute the values $S_{i}$ and $R_{i} ; \mathrm{i}=1,2, \ldots, \mathrm{m}$, from the following relations:

$$
\begin{aligned}
& S_{i}=\sum_{j=1}^{n} w_{j}\left(f_{j}^{*}-f_{i j}\right) /\left(f_{j}^{*}-f_{j}^{-}\right), i=1, \ldots, m, j=1, \ldots, n \\
& R_{i}=\max _{j}\left[w_{j}\left(f_{j}^{*}-f_{i j}\right) /\left(f_{j}^{*}-f_{j}^{-}\right)\right], i=1, \ldots, m, j=1, \ldots, n \quad(10)
\end{aligned}
$$

where $w_{j}$ represents the weight of each criterion.

- Third step: Compute the VIKOR index

In this step, the $Q_{i}$ values are calculated using Eq. 11 as follows:

$$
\begin{aligned}
& Q_{i}=v\left[\frac{\left(S_{i}-S^{*}\right)}{\left(S^{-}-S^{*}\right)}\right]+(1-v)\left[\frac{\left(R_{i}-R^{*}\right)}{\left(R^{-}-R^{*}\right)}\right], i=1,2, \ldots, m \\
& \text { Where }^{*}=\min _{i} S_{i} ; S^{-}=\max _{i} S_{i} ; R^{*}=\min _{i} R_{i} ; R^{-}=\max _{i} R_{i}, v=0.5
\end{aligned}
$$

- Fourth step: Rank the options based on the Q, S, and R values. The results previde three ranking lists.

- Fifth step: In this step, the option with the lowest Q value is recommended as the best option, in case the two following conditions are met: 
- First condition: The following relation should hold true for Options $a$ and $b$ as the two top options (based on the lowest Q value):

$Q(b)-Q(a) \geq \frac{1}{m-1}$, where $m$ is the number of feasible alternatives (12)

- Second condition: After ranking the options based on R and S values, Option $a$ should also be the top rank in either the $\mathrm{R}$ and $\mathrm{S}$ groups.

For a better comparison, the values of R, S and Q are plotted in Fig. 7 for each building.

Friction Damper

Load-Core Rubber Bearing (LRB)

Tuned Mass Damper (TMD)

Viscous Damper

Viscoelastic Damper
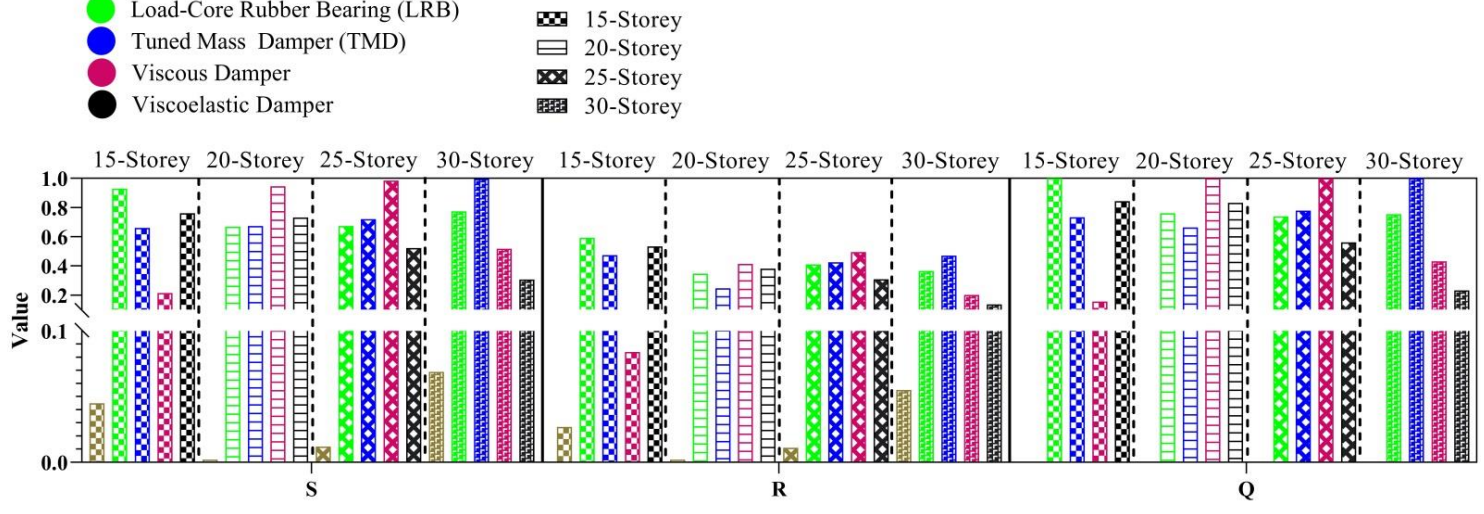

Figure 7. Results obtained for R, S, and Q for each building

The ranking results based on the VIKRO method are presented in Table 15. As shown, the results from this method and those of the SECA method are well consistent. In both methods, the friction damper ranked first for all buildings.

\begin{tabular}{l} 
Table 15. Raking results for the options based on the \\
VIKRO method \\
\hline System \\
\cline { 2 - 4 }
\end{tabular}




\begin{tabular}{c|llll}
\cline { 2 - 4 } Friction & 1 & 1 & 1 & 1 \\
LRB & 5 & 3 & 3 & 4 \\
TMD & 3 & 2 & 4 & 5 \\
Viscous & 2 & 5 & 5 & 3 \\
Vis. Elastic & 4 & 4 & 2 & 2 \\
\hline
\end{tabular}

\section{Conclusion}

Commented [YJ24]: Require rewriting

This study aimed to select best retrofitting method to improve the seismic behavior of RC shear wall buildings. In this regard, the following conclusions can be drawn.

- In order to control and dissipate the input energy applied to the building from earthquakes, five types of passive seismic control systems were used, namely the tuned mass damper (TMD), viscoelastic damper, friction damper, viscous damper, and the lead-core rubber bearing.

- Four buildings with different numbers of stories (15 to 30 ) were modeled in the OpenSees software package along with their passive seismic control systems.

- The buildings were analyzed using the non-linear time-history analysis under 50 different earthquake records.

- Given the complexity of ranking the passive seismic control systems, the effect of different parameters, such as structural specifications, the frequency content of the earthquake record, specifications of the passive control systems, and the effect of higher modes, was investigated on the response of high-rise buildings.

- The newly proposed SECA method, as well as the well-known VIKOR method, were used to rank the available options. A new index was defined to relate the input (earthquake) and output (structural responses such as displacement, drift, acceleration, velocity, and base 
shear), and the resulting values obtained for the indices based on the considered criteria were used to form the decision matrix for each building.

- The results obtained from both methods were very close. Based on the considered criteria and problem conditions, the friction damper was found to offer the best performance among the passive control systems. However, note that criteria such as construction costs and execution were not considered in this study since the cost of the passive control systems was dependent on the building location and the respective country.

- The passive control system's cost can vary in different countries and even the cities within the same country.

- The results showed that the multiple-criteria decision-making (MCDM) methods could be used for selecting the building retrofitting methods or improve their performance in the analysis and design.

- The MCDM methods provide the opportunity to implicitly take into account the structural specifications, the frequency content of the earthquake record, specifications of the passive control systems, the effect of higher modes, and complex decision-making factors in the decision-making process.

\section{Fund}

This research did not receive any specific grant from funding agencies in the public, commercial, or not-for-profit sectors.

\section{Conflict of Interest}

The author confirms that there is no conflict of interest. 


\section{References}

1- Xu Z, Lu X, Cheng Q, Guan H, Deng L, Zhang Z. A smart phone-based system for postearthquake investigations of building damage. International journal of disaster risk reduction. 2018 Mar 1;27:214-22.

2- Xiong C, Lu X, Lin X. Damage assessment of shear wall components for RC frame-shear wall buildings using story curvature as engineering demand parameter. Engineering Structures. 2019 Jun 15;189:77-88.

3- Sritharan S, Beyer K, Henry RS, Chai YH, Kowalsky M, Bull D. Understanding poor seismic performance of concrete walls and design implications. Earthquake Spectra. 2014 Feb;30(1):307-34.

4- Wallace JW. Behavior, design, and modeling of structural walls and coupling beamsLessons from recent laboratory tests and earthquakes. International Journal of Concrete Structures and Materials. 2012 Mar;6(1):3-18.

5- Pavel F, Nica G. Influence of rotating strong ground motions on the response of doubly symmetrical RC wall structures in Romania and its implication on code provisions. International Journal of Civil Engineering. 2019 Jul;17(7):969-79.

6- Arroyo P, Tommelein ID, Ballard G. Comparing AHP and CBA as decision methods to resolve the choosing problem in detailed design. Journal of construction engineering and management. 2015 Jan 1;141(1):04014063. 
7- Zavadskas EK, Antuchevičienė J, Kapliński O. Multi-criteria decision making in civil engineering: Part I-a state-of-the-art survey. Engineering Structures and Technologies. 2015 Jul 3;7(3):103-13.

8- Zavadskas EK, Antuchevičienė J, Kapliński O. Multi-criteria decision making in civil engineering. Part II-applications. Engineering Structures and Technologies. 2015 Oct 2;7(4):151-67.

9- Antucheviciene, J., Kala, Z., Marzouk, M., \& Vaidogas, E. R. (2015). Solving civil engineering problems by means of fuzzy and stochastic MCDM methods: current state and future research. Mathematical Problems in Engineering, 2015.

10-Medineckiene, M., Zavadskas, E. K., Björk, F., \& Turskis, Z. (2015). Multi-criteria decision-making system for sustainable building assessment/certification. Archives of Civil and Mechanical Engineering, 15(1), 11-18.

11-Zavadskas EK, Antucheviciene J, Vilutiene T, Adeli H. Sustainable decision-making in civil engineering, construction and building technology. Sustainability. 2018 Jan;10(1):14.

12-GÜLBANDILAR E, AKYOL SÖ, Koçak Y. Multi-criteria decision making for cement mortar mixture selection by fuzzy topsis. Eskişehir Osmangazi Üniversitesi Mühendislik ve Mimarlık Fakültesi Dergisi. 2019;27(2):77-84.

13- Formisano A, Mazzolani FM. On the selection by MCDM methods of the optimal system for seismic retrofitting and vertical addition of existing buildings. Computers \& Structures. 2015 Oct 15;159:1-3.

14-Formisano A, Castaldo C, Chiumiento G. Optimal seismic upgrading of a reinforced concrete school building with metal-based devices using an efficient multi-criteria 
decision-making method. Structure and Infrastructure Engineering. 2017 Nov 2;13(11):1373-89.

15-Miano A, Chiumiento G, Saggese A. Structural assessment and upgrading for an old building belonging to an historical multi-sports center in Naples. Frontiers in Built Environment. 2019 Mar 15;5:23.

16- Barkhordari MS, Tehranizadeh M. Ranking Passive Seismic Control Systems by Their Effectiveness in Reducing Responses of High-Rise Buildings with Concrete Shear Walls Using Multiple-Criteria Decision Making. International Journal of Engineering. 2020 Aug 1;33(8):1479-90.

17-Çelikbilek Y, Tüysüz F. An in-depth review of theory of the TOPSIS method: An experimental analysis. Journal of Management Analytics. 2020 Apr 2;7(2):281-300.

18- Ahmed M. Fluid viscous dampers locations in reinforced-concrete core wall buildings. Proceedings of the Institution of Civil Engineers-Structures and Buildings. 2017 Jan;170(1):33-50.

19- Faridani HM, Capsoni A. Investigation of the effects of viscous damping mechanisms on structural characteristics in coupled shear walls. Engineering Structures. 2016 Jun 1;116:121-39.

20-Hejazi F, Ostovar N, Bashir A. Seismic response of shear wall with viscous damping system. InGlobal Civil Engineering Conference 2017 Jul 25 (pp. 595-607). Springer, Singapore.

21-Reza MS, Jaafar K, Shams S, Azad AK. Tube shear wall interaction of high rise building and influence of damper on its dynamic behavior. 
22- Wang W, Li A, Wang X. Seismic performance of base-isolated precast concrete shear wall structure with AHW connections. Shock and Vibration. 2018 Jan 1;2018.

23- Osgooei PM, Tait MJ, Konstantinidis D. Seismic isolation of a shear wall structure using rectangular fiber-reinforced elastomeric isolators. Journal of Structural Engineering. 2016 Feb 1;142(2):04015116.

24- ACI Committee, International Organization for Standardization. Building code requirements for structural concrete (ACI 318-08) and commentary. American Concrete Institute.

25- AISC (American Institute of Steel Construction). Seismic provisions for structural steel buildings. Chicago: AISC.

26- ASCE. Minimum design loads for buildings and other structures. American Society of Civil Engineers.

27- Mazzoni S, McKenna F, Scott MH, Fenves GL. OpenSees command language manual. Pacific Earthquake Engineering Research (PEER) Center. 2006 Jul 19;264.

28- McKenna F, Scott MH, Fenves GL. Nonlinear finite-element analysis software architecture using object composition. Journal of Computing in Civil Engineering. 2010 Jan;24(1):95107.

29-Dabaghi M, Saad G, Allhassania N. Seismic collapse fragility analysis of reinforced concrete shear wall buildings. Earthquake Spectra. 2019 Feb;35(1):383-404.

30- Takewaki I. Building control with passive dampers: optimal performance-based design for earthquakes. John Wiley \& Sons; 2011 Sep 23.

31- Badkoubeh A, Massumi A. Fundamental period of vibration for seismic design of concrete shear wall buildings. Scientia Iranica. 2017 Jun 1;24(3):1010-6. 
32- Akçelyan S, Lignos D. Dynamic Analyses of 1-Story Moment Frame with Viscous Dampers.

33- Aiken ID, Nims DK, Whittaker AS, Kelly JM. Testing of passive energy dissipation systems. Earthquake spectra. 1993 Aug;9(3):335-70.

34-Kikuchi M, Nakamura T, Aiken ID. Three-dimensional analysis for square seismic isolation bearings under large shear deformations and high axial loads. Earthquake engineering \& structural dynamics. 2010 Oct 25;39(13):1513-31.

35- Kikuchi M, Aiken ID, Kasalanati A. Simulation analysis for the ultimate behavior of fullscale lead-rubber seismic isolation bearings. In15th world conference on earthquake engineering 2012 (Vol. 24)

36- Barkhordari MS, Tehranizadeh M, Scott MH. Numerical modelling strategy for predicting the response of reinforced concrete walls using Timoshenko theory. Magazine of Concrete Research. 2021 Jan 7:1-23.

37- Bathaei A, Ramezani M, Ghorbani-Tanha AK. Vibration control of the College Bridge using tuned mass dampers. Modares Civil Engineering journal. 2017 Feb 10;16(20):21-32.

38- Afzali A, Mortezaei A, Kheyroddin A. Seismic Performance of High-Rise RC Shear Wall Buildings Subjected to Ground Motions with Various Frequency. Civil Engineering Journal. 2017 Aug;3(8).

39- FEMA P6. Quantification of building seismic performance factors.

40- Keshavarz-Ghorabaee M, Amiri M, Zavadskas EK, Turskis Z, Antucheviciene J. Simultaneous evaluation of criteria and alternatives (SECA) for multi-criteria decisionmaking. Informatica. 2018 Jan 1;29(2):265-80. 
41- Keshavarz Ghorabaee, M. The LINGO code and instructions for SECA. 2018; Available from:

https://figshare.com/articles/The_LINGO_code_and_instructions_for_SECA/5830623/1

42- Tabeshpour MR, Ebrahimian H. Seismic retrofit of existing structures using friction dampers.

43-Luo H, Ikago K, Chong C, Keivan A, Phillips BM. Performance of low-frequency structures incorporated with rate-independent linear damping. Engineering Structures. 2019 Feb 15;181:324-35.

44- Akhlagh Pasand A, Fatollah Pour A, Zahrai SM. Comparing performance of TMD and MTMD vertically distributed in height for multi-modal seismic control of tall buildings. Amirkabir Journal of Civil Engineering. 2019 Aug 4;52(10):12-.

45- Ma CF, Zhang YH, Tan P, Zhou FL. Seismic response of base-isolated high-rise buildings under fully nonstationary excitation. Shock and Vibration. 2014 Jan 1;2014.

46- Khaji N. Seismic response of base-isolated high-rise buildings under long-period ground motions. Modares Civil Engineering journal. 2016 Jun 10;16(2):41-52.

47-Opricovic S, Tzeng GH. Compromise solution by MCDM methods: A comparative analysis of VIKOR and TOPSIS. European journal of operational research. 2004 Jul $16 ; 156(2): 445-55$.

48- Hanson RD, Soong TT. Seismic design with supplemental energy dissipation devices. Earthquake Engineering Research Institute; 2001.

49- Rodriguez ME, Restrepo JI, Carr AJ. Earthquake-induced floor horizontal accelerations in buildings. Earthquake engineering \& structural dynamics. 2002 Mar;31(3):693-718. 
50- Pacific Earthquake Engineering Research Center. Guidelines for Performance-Based $\underline{\text { Seismic Design of Tall Buildings. } 2017 .}$

51- Armali M, Damerji H, Hallal J, Fakih M. Effectiveness of friction dampers on the seismic behavior of high rise building VS shear wall system. Engineering Reports. 2019 Dec;1(5):e12075.

52-Kordi F, Alamatian J. Analytical method for designing the tuned mass damper based on the complex stiffness theory. Iranian Journal of Science and Technology, Transactions of Civil Engineering. 2019 Dec;43(4):673-84.

53- Naeim F, Kelly JM. Design of seismic isolated structures: from theory to practice. John Wiley \& Sons; 1999 Mar 25.

54- Takewaki I. Building control with passive dampers: optimal performance-based design for earthquakes. John Wiley \& Sons; 2011 Sep 23.

55- Caterino N, Iervolino I, Manfredi G, Cosenza E. Multi-criteria decision making for seismic retrofitting of RC structures. Journal of Earthquake Engineering. 2008 May 2;12(4):55583.

56- Formisano A, Castaldo C, Chiumiento G. Optimal seismic upgrading of a reinforced concrete school building with metal-based devices using an efficient multi-criteria decision-making method. Structure and Infrastructure Engineering. 2017 Nov 2;13(11):1373-89.

\section{Appendix A}




\begin{tabular}{cccc}
\hline \multicolumn{4}{c}{ Table A.1. Frame section of the prototype buildings } \\
\hline Building & No. of story & Column $(\mathrm{cm})$ & Beam \\
\hline \multirow{3}{*}{15 -story } & $1-5$ & $20 \times 20 \times 2.5$ & IPE550 \\
& $6-10$ & $20 \times 20 \times 2$ & IPE550 \\
& $11-15$ & $18 \times 18 \times 2$ & IPE400 \\
\hline \multirow{4}{*}{20 -story } & $1-5$ & $24 \times 24 \times 2.5$ & IPE600 \\
& $6-10$ & $22 \times 22 \times 2$ & IPE600 \\
& $11-15$ & $20 \times 20 \times 2$ & IPE500 \\
& $16-20$ & $20 \times 20 \times 1.6$ & IPE500 \\
\hline \multirow{4}{*}{25 -story } & $1-5$ & $26 \times 26 \times 3$ & IPE750 \\
& $6-10$ & $26 \times 26 \times 2$ & IPE750 \\
& $11-15$ & $24 \times 24 \times 3$ & IPE550 \\
& $16-20$ & $20 \times 20 \times 2.5$ & IPE550 \\
& $21-25$ & $20 \times 20 \times 2$ & IPE550 \\
\hline \multirow{5}{*}{30 -story } & $1-5$ & $28 \times 28 \times 3.5$ & IPE750 \\
& $6-10$ & $26 \times 26 \times 3$ & IPE750 \\
& $11-15$ & $24 \times 24 \times 3.5$ & IPE750 \\
& $16-20$ & $24 \times 24 \times 2$ & IPE550 \\
& $21-25$ & $22 \times 22 \times 2.5$ & IPE550 \\
& $26-30$ & $20 \times 20 \times 2$ & IPE550 \\
\hline
\end{tabular}

Table A.2. Shear wall section of the prototype buildings

\begin{tabular}{|c|c|c|c|c|}
\hline Building & $\begin{array}{l}\text { No. of } \\
\text { story }\end{array}$ & $\begin{array}{l}\text { Thickness } \\
(\mathrm{cm})\end{array}$ & $\begin{array}{c}\text { longitudinal } \\
\text { Reinforcement } \\
(\mathrm{cm})\end{array}$ & $\begin{array}{c}\text { Transverse } \\
\text { Reinforcement } \\
\mathrm{cm}^{2} / \mathrm{m} \\
\end{array}$ \\
\hline \multirow{3}{*}{15 -story } & $1-5$ & 30 & \#5@20 & 7.5 \\
\hline & $6-10$ & 30 & \#4@25 & 6.3 \\
\hline & $11-15$ & 25 & \#4@25 & 6.3 \\
\hline \multirow{4}{*}{20 -story } & $1-5$ & 35 & \#6@20 & 8.8 \\
\hline & $6-10$ & 30 & \#5@20 & 7.5 \\
\hline & $11-15$ & 25 & \#4@20 & 6.3 \\
\hline & $16-20$ & 25 & \#4@25 & 6.3 \\
\hline \multirow{5}{*}{25 -story } & $1-5$ & 35 & \#6@15 & 8.8 \\
\hline & $6-10$ & 30 & \#6@20 & 7.5 \\
\hline & $11-15$ & 30 & \#5@20 & 7.5 \\
\hline & $16-20$ & 30 & \#4@20 & 7.5 \\
\hline & $21-25$ & 25 & \#4@25 & 6.3 \\
\hline \multirow{6}{*}{30 -story } & $1-5$ & 35 & \#7@20 & 8.8 \\
\hline & $6-10$ & 35 & \#6@20 & 8.8 \\
\hline & $11-15$ & 30 & \#5@20 & 7.5 \\
\hline & $16-20$ & 30 & \#5@25 & 7.5 \\
\hline & $21-25$ & 25 & \#4@20 & 6.3 \\
\hline & 26-30 & 25 & \#4@25 & 6.3 \\
\hline
\end{tabular}

